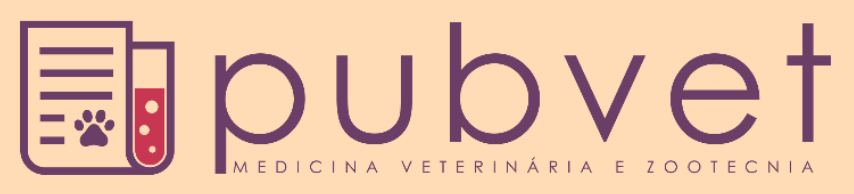

https://doi.org/10.31533/pubvet.v13n01a241.1-10

\title{
Estresse hídrico em plantas forrageiras: Uma revisão
}

\author{
George do Nascimento Araújo Júnior ${ }^{1 *}$, Fabiana Torres Gomes $^{2}$, Marcelo José da Silva $^{2}$, \\ Alexandre Maniçoba Ferraz da Rosa Jardim ${ }^{1}$, Vicente José Laamon Pinto Simões ${ }^{1}{ }^{\bullet}$, José \\ Lypson Pinto Simões Izidro ${ }^{1}$, Maurício Luiz de Mello Vieira Leite $^{3 \bullet}$, Vicente Imbroisi \\ Teixeira3 $^{\ominus}$, Thieres George Freire da Silva ${ }^{3}$ \\ ${ }^{I}$ Mestrando em Produção Vegetal, Universidade Federal Rural de Pernambuco, Unidade Acadêmica de Serra Talhada - PE Brasil \\ ${ }^{2}$ Mestrando em Engenharia Agrícola, Universidade Federal do Vale do São Francisco - PE Brasil. \\ ${ }^{3}$ Professor da Universidade Federal Rural de Pernambuco, Unidade Acadêmica de Serra Talhada - PE Brasil. \\ *Autor para correspondência: georgearaujo.agro@gmail.com
}

Resumo. A água é um dos recursos determinante para o funcionamento e crescimento pleno das plantas, ao mesmo tempo em que é considerado o mais limitante. Nesse sentido, um dos principais fatores causador de estresse nas plantas é a disponibilidade hídrica. O conhecimento do desempenho das plantas forrageiras em condições de estresse hídrico é de grande valia para entendimento do efeito do período "seco" na produção de forragem, permitindo assim o uso de práticas de manejo viáveis para melhorar o cultivo durante esse período. Desta forma, objetivou-se com esta revisão discorrer sobre as respostas das plantas forrageiras submetidas ao estresse hídrico, destacando os efeitos causados e mecanismos de adaptação dessas plantas, assim como práticas para a convivência com o déficit hídrico.

Palavras chave: Água, disponibilidade hídrica, forragem, tolerância

\section{Water stress in forage plants: A review}

Abstract. Water is one of the determining resources for the full functioning and growth of plants, while it is considered the most limiting. In this sense, one of the main factors causing stress in plants is water availability. Knowledge of the performance of forage plants under conditions of water stress is of great value for understanding the effect of the dry period on forage production, thus allowing the use of viable management practices to improve cultivation during this period. Thus, the purpose of this review was to discuss the responses of forage plants submitted to water stress, highlighting the effects caused and mechanisms of adaptation of these plants, as well as practices for coexistence with the water deficit.

Keywords: Water, water availability, forage, tolerance

\section{Estrés hídrico en plantas forrajeras: Una revisión}

Resumen. El agua es uno de los recursos determinantes para el funcionamiento y crecimiento pleno de las plantas, al mismo tiempo que es considerado el más limitante. En ese sentido, uno de los principales factores causantes de estrés en las plantas es la disponibilidad hídrica. El conocimiento del desempeño de las plantas forrajeras en condiciones de estrés hídrico es de gran valor para entender el efecto del período "seco" en la producción de forraje, permitiendo así el uso de prácticas de manejo viables para mejorar el cultivo durante ese período. De esta forma, se objetivó con esta revisión discurrir sobre las respuestas de las plantas forrajeras sometidas al estrés hídrico, 
destacando los efectos causados y mecanismos de adaptación de esas plantas, así como prácticas para la convivencia con el déficit hídrico.

Palabras clave: Agua, disponibilidad hídrica, forraje, tolerancia

\section{Introdução}

As plantas forrageiras têm participação expressiva na produção de leite e de carne, pois atuam como a fonte de alimento para os rebanhos, sendo consideradas um dos principais fatores para o desenvolvimento da pecuária em todo o mundo. No Brasil, a sua extensa faixa territorial possibilita regiões com fatores climáticos intrínsecos, possibilitando o cultivo dessas plantas em diferentes condições de estresses (Santos et al., 2008; Silva et al., 2011). De acordo com Monteiro et al., (2014), os danos ocasionados pelos fatores abióticos são considerados os que mais limitam as atividades agrícolas. Logo, a exploração pecuária fica estagnada em decorrência do suprimento irregular de forragem, uma vez que dependem de condições adequadas para boa produtividade (Silva et al., 2011). Nesse sentido, os estresses abióticos têm despertado interesse de vários pesquisadores, por serem responsáveis pelos fortes impactos sobre o crescimento e produtividade das plantas. Dentre estes fatores, o estresse ocasionado por deficiência hídrica se destaca por ser comum nos ecossistemas e por ocasionar sérias disfunções nas plantas, sejam eles pelo decréscimo de turgor das células, que é essencial nos processos metabólicos, ou por causar alterações morfológicas, fisiológicas e bioquímicas, refletindo sobre o transporte e absorção de água e nutrientes pelas mesmas (Araújo Filho \& Carvalho 1997; Monteiro et al., 2014).

Do ponto de vista prático, os efeitos ocasionados pela deficiência hídrica causam preocupações aos técnicos e produtores, isso em decorrência dos danos ocasionados a todos os estádios de desenvolvimento das culturas (Cavalcante et al., 2009). No entanto, tais efeitos dependem do grau de intensidade do estresse (Araújo Filho et al., 1995; Araújo Filho \& Carvalho 1997) e da espécie cultivada, podendo essas plantas desenvolver mecanismos de tolerância ou até mesmo de adaptação às tais condições (Silva et al., 2011), minimizando assim os prejuízos. De acordo com Silva et al., (2011), apesar de apresentarem certa tolerância ao estresse decorrente da deficiência hídrica, foi possível observar alterações no desenvolvimento e crescimento de plantas forrageiras. Nesse caso foi possível observar ainda uma maior tolerância do sorgo às condições de estresse hídrico, seja ele por deficiência ou alagamento. Ao avaliar diferentes genótipos de Capim-Elefante anão, Araújo Filho et al., (1995) observaram que o genótipo CNPGL 94-34-3 foi o que apresentou maior tolerância ao estresse hídrico.

O conhecimento do desempenho das plantas forrageiras em condições de estresse hídrico é de grande valia para auxiliar no entendimento do efeito do período "seco" na produção de forragem, permitindo assim o uso de práticas de manejo viáveis para melhorar o cultivo durante esse período. Desta forma, o objetivo desta revisão é discorrer sobre as respostas das plantas forrageiras submetidas ao estresse hídrico, destacando os efeitos causados e mecanismos de adaptação dessas plantas, assim como práticas para a convivência com o déficit hídrico.

\section{Água}

A água é uma das principais e mais abundantes substâncias presentes na superfície terrestre, sendo o meio responsável para o desenvolvimento de toda atividade celular (Lehninger 2006). Considerada como fundamental constituinte vegetal, compõe cerca de $95 \%$ da biomassa verde das plantas, sendo de significativa importância para a manutenção da integridade funcional de moléculas biológicas, células, tecidos e organismos (Taiz \& Zeiger 2009; Chavarria \& Santos 2012).

Juntamente com a temperatura, a água é o recurso determinante para o funcionamento e crescimento pleno das plantas, ao mesmo tempo em que é considerado também como o mais limitante, uma vez que constitui a matriz e o meio onde ocorre a maioria dos processos bioquímicos essenciais à vida dos vegetais (Lehninger 2006). Logo, tanto a distribuição natural das plantas na superfície da terra, como a produtividade agrícola são decorrentes da disponibilidade de água (Pimentel 2004; Taiz \& Zeiger 2009; Santos et al., 2011). A água é um essencial reagente ou substrato para vários processos, como por exemplo, a hidrólise do amido em açúcares solúveis, que é imprescindível na germinação de sementes ou na respiração noturna, uma vez que não há produção de carboidratos pela 
fotossíntese. No processo fotossintético, a água é demandada na liberação de prótons e elétrons da etapa fotoquímica, assim como na regulação da abertura e fechamento estomático, possibilitando a absorção de $\mathrm{CO}_{2}$ e a mobilização de foto-assimilados pela planta (Chavarria \& Santos 2012). A água atua também como a fonte do oxigênio molecular existente na atmosfera, que é produzido na fotossíntese, assim como do hidrogênio utilizado para síntese de carboidratos a partir da redução do $\mathrm{CO}_{2}$ (Pimentel 2004).

Outra função da água é a manutenção da turgescência da célula, responsável pela sustentação da morfologia de plantas herbáceas e a movimentação das folhas e flores, além de promover o alongamento celular, as trocas gasosas nas folhas e o transporte no floema. Porém, em caso de desidratação das células, ocorre a perda de turgor, que por sua vez provoca o fechamento estomático e consequente redução da fotossíntese e respiração (Pimentel 2004). Outra importante função está relacionada com o movimento e absorção de nutrientes essenciais para as plantas, pelo processo conhecido como fluxo de massa (Taiz \& Zeiger 2009).

\section{Relação solo $x$ água $x$ planta $x$ atmosfera}

Para suprir suas necessidades metabólicas, as plantas precisam renovar a água que foi transferida para a atmosfera, com o intuito de manter a turgescência das suas folhas e raízes de forma a assegurar sua sobrevivência. Dessa forma, a perda de água pela transpiração deve ser reposta pela absorção de uma quantidade equivalente de água. No geral, muitas plantas podem absorver a umidade presente na atmosfera na forma de névoa ou orvalho, porém, esse mecanismo se torna insignificante quando comparado com a absorção de água do solo pelo sistema radicular (Cavalcante et al., 2009; Chavarria \& Santos 2012). A absorção de água pelas raízes está relacionada à superfície que está diretamente em contato com o solo (rizosfera). Portanto, as raízes maiores e mais jovens, que apresentam uma maior quantidade de raízes secundária, são imprescindíveis para aumentar a superfície de contato e assim melhorar a capacidade de absorção de água presente no solo. Além disso, a distribuição e proporção das raízes é muito importante para atender a demanda de água de uma planta (Chavarria \& Santos 2012).

O movimento da água no sentido epiderme para endoderme da raiz pode ocorrer pela via apoplástica, via simplástica e de forma transmembranar (Figura 1). Na primeira, a água se move pelos espaços intercelulares e não passa por quaisquer membranas. Já na via simplástica, a água se move exclusivamente de uma célula para as outras pelas conexões, denominadas plasmodesmas. Na forma transmembranar, ocorre um movimento misto envolvendo as duas primeiras vias, aonde a água vai em uma direção pelo tecido radicular, entrando via simplástica e saindo das células de forma apoplástica. Alguns estudos ainda estão sendo realizados visando encontrar a importância relativa destes caminhos. Porém, existem algumas evidências de que as plantas que apresentam baixa taxa de transpiração, a via de transporte predominante é a simplástica, enquanto aquelas que apresentam alta taxa de transpiração ocorrem em maior proporção o transporte apoplástico (Chavarria \& Santos 2012).

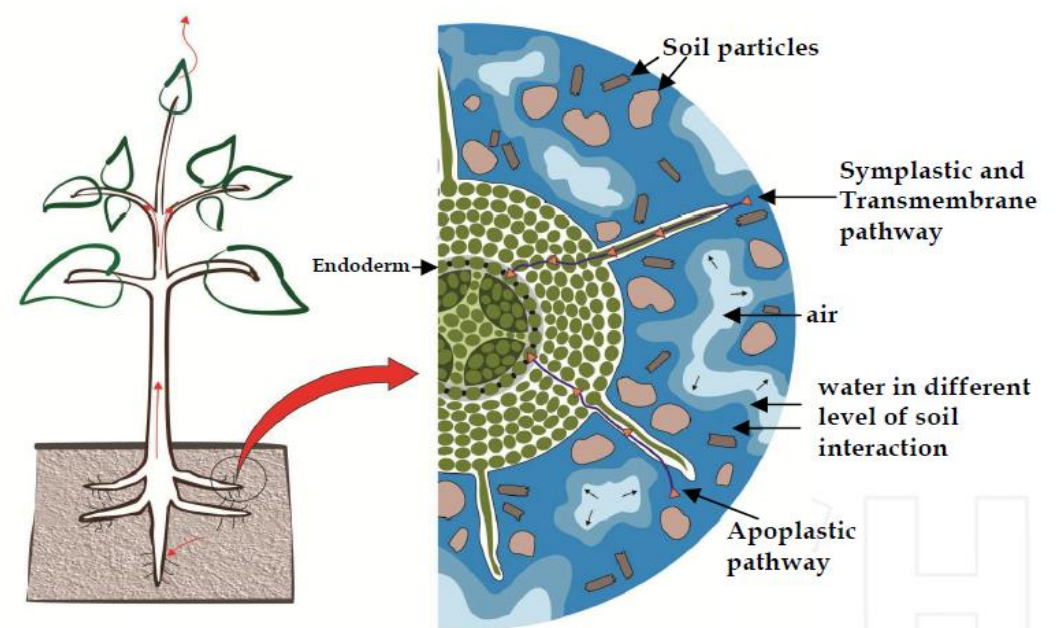

Figura 1. Detalhe da rizosfera. Absorção de água pela raiz pelas vias apoplástica, simplástica e transmembranar. Fonte: Chavarria \& Santos (2012). 
A perda de água das plantas é causada pelo gradiente de pressão formado entre as folhas e a atmosfera, sendo influenciado diretamente pela disponibilidade de água presente no solo. Desta forma, a medida que a disponibilidade hídrica diminui, aumenta a dificuldade de absorção de água pelas raízes das plantas, ocasionando perda de turgor e murchamento das mesmas, uma vez que a planta não consegue equilibrar a perda de água ocasionada pela transpiração. Todavia, ao ponto que a demanda atmosférica aumenta, maior será a necessidade de absorção rápida de água pela planta e, consequentemente, maior fluxo vertical de água no sistema solo-água-planta-atmosfera. Assim, as variações neste gradiente definem a exigência de água requerida pelas plantas no meio onde elas se encontram (Marenco \& Lopes 2005; Chavarria \& Santos 2012; Duque et al., 2013).

A substituição da vegetação natural por pastagens sugere mudanças graduais na energia hídrica do sistema, provocada pela compactação dos solos pelo pastejo dos animais. Nesse sentido, um dos problemas ocasionados é a diminuição da capacidade de infiltração, ao mesmo tempo em que há o aumento do escoamento superficial, contribuindo para diminuição do potencial de armazenamento de água nos solos. Dessa forma, a mudança do regime hídrico em função da diminuição da capacidade de infiltração, se torna mais um fator a favor do estresse hídrico por ocasião da pouca disponibilidade de água no solo (Cavalcante et al., 2009).

\section{Estresse hídrico em plantas forrageiras}

As plantas podem estar submetidas a vários tipos de estresses ambientais (Angelocci 2002). Segundo Jones and Jones (1989), o estresse, numa visão geral, pode ser definido como uma pressão excessiva de algum fator adverso que tende a dificultar o funcionamento normal dos sistemas. Do ponto de vista botânico, o estresse é definido como um significativo desvio das condições normais para a vida da planta, resultando em mudanças e respostas aos níveis do organismo (Blum et al., 1991). Nesse contexto, um dos principais fatores causador de estresse nas plantas é a disponibilidade hídrica. As plantas podem sofrer danos tanto por excesso como por falta de água. No entanto, o estresse ocasionado por deficiência é mais comum, afetando, sobretudo a produtividade e persistência das mesmas (Cavalcante et al., 2009). Segundo Oliveira et al., (2015) a disponibilidade hídrica tem sido um dos limitantes para evolução das espécies. Desta forma, a habilidade para lidar com o déficit hídrico é um importante determinante de seleção natural das plantas e produtividade das culturas agrícolas. O termo estresse hídrico comumente é definido como um fator externo, que exerce uma influência negativa sobre as plantas. Assim, o estresse hídrico pode ser descrito como todo o conteúdo de água de um tecido ou célula que está abaixo do conteúdo de água máximo exibido quando a planta apresenta-se no estado de maior hidratação (Taiz \& Zeiger 2009).

Os efeitos causados pelo estresse hídrico provocam mudanças na anatomia, fisiologia e bioquímica das plantas, com intensidade dependente do tipo de planta e do grau de duração as quais foram submetidas ao estresse (Araújo et al., 2010), podendo afetar todos os seus estágios de desenvolvimento, partindo da germinação das sementes e, consequente estabilização do estande (Balardin et al., 2011), até o desenvolvimento e produtividade (Costa et al., 2008; Taiz \& Zeiger 2009; Bilibio et al., 2010). Santos et al., (2013) observaram reduções nos valores de massa seca de rebentos, folhas e haste de Brachiaria brizantha, submetida ao estresse por déficit hídrico, o que afetou produção de massa de forragem. Do ponto de vista fisiológico e bioquímico, o déficit hídrico afeta a fotossíntese das plantas em decorrência dos efeitos estomáticos e não estomáticos (Araújo et al., 2010). Em situações em que o estresse é considerado leve ou moderado, o efeito estomático prevalece, diminuindo a fotossíntese pelo aumento da resistência à difusão do $\mathrm{CO}_{2}$ (Galmés et al., 2011). Smit \& Singels (2006) associam o aumento da resistência devido ao fechamento estomático em função da diminuição do potencial de água na folha e redução do conteúdo de água no solo, ou ainda em resposta a elevada demanda atmosférica (Endres et al., 2010). Nesse caso, o fechamento estomático pode ser o indicador mais sensível do estresse do que mesmo a perda de turgor. Por outro lado, o efeito não estomático relaciona-se com os processos fotoquímicos e bioquímicos. No primeiro, o estresse hídrico reduz o transporte de elétrons e afeta a síntese de ATP e NADPH, enquanto que nos processos bioquímicos, há uma redução da eficiência carboxilativa e, ou na quantidade e atividade das enzimas responsáveis pelo metabolismo fotossintético, principalmente a rubisco (Taiz \& Zeiger 2009). 
Araújo et al., (2010) relataram que os genótipos de capim-elefante anão submetidos ao estresse, apresentaram menores valores de fotossíntese líquida (Figura 2). Taiz \& Zeiger (2009) descreveram que muitos processos fisiológicos das plantas, como a abertura e fechamento estomático e, consequentemente, a fotossíntese, são ajustados principalmente pela força de turgescência das células.

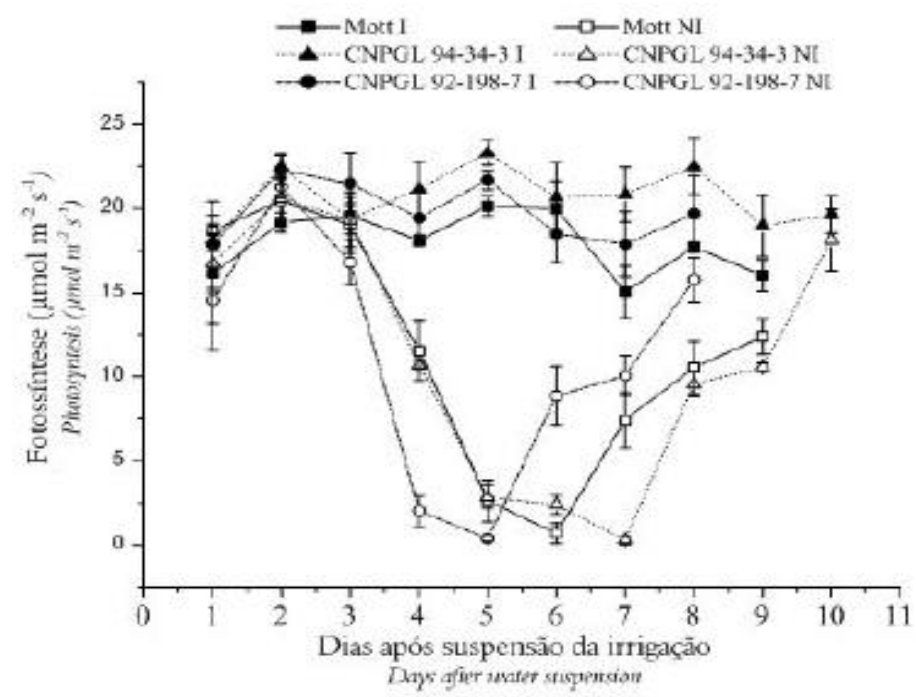

Figura 2. Fotossíntese líquida de genótipos de Capim-elefante anão irrigado (I) e não irrigado (NI). Fonte: Araújo et al., (2010).

\section{Mecanismos de adaptação, tolerância e aclimatação das plantas forrageiras ao estresse hídrico}

As plantas apresentam mecanismos fisiológicos e anato morfológicos que as fazem tolerar, se adaptar e aclimatar-se ao estresse hídrico, principalmente ao déficit. No geral, a adaptação pode ser caracterizada como uma resistência adquirida geneticamente por meio da seleção de gerações anteriores. Dessa forma, o termo adaptação deve ser diferenciado da denominação aclimatação, que por sua vez é o aumento da tolerância da planta em função da sua exposição a determinado estresse (Taiz \& Zeiger 2009).

As estratégias utilizadas pelas plantas para sobreviverem em situações de déficit hídrico podem ser divididas em escape, retardo e tolerância. $\mathrm{O}$ primeiro pode ser caracterizado pelo rápido desenvolvimento fenológico das plantas, de forma que completem o seu ciclo antes que os problemas oriundos do estresse se tornem severos o bastante para provocar danos. O retardo por sua vez, está relacionado com a manutenção do turgor e volume celular, ocasionados pelo desenvolvimento de um eficiente sistema radicular para absorção de água e pela diminuição da perda de água para atmosfera, que é decorrente do aumento do espessamento das paredes celulares e da cerosidade da cutícula. Por fim, a tolerância está associada à capacidade da planta em manter suas funções fisiológicas mesmo em condições de déficit hídrico (Conforto 2008).

As formas de adaptação e de aclimatação ao estresse hídrico são resultantes de eventos associados que ocorrem desde o nível anatômico e morfológico até o celular, bioquímico e molecular. Como exemplo, a murcha de folhas em resposta ao déficit hídrico, reduz a perda de água pela folha e também a exposição à luz incidente, diminuindo o estresse pelo calor (Taiz \& Zeiger 2009). Por outro lado, algumas plantas adotam a estratégia de diminuir a área foliar a fim de favorecer o aumento do sistema radicular, de forma a se adaptarem a pouca disponibilidade hídrica. No entanto, essa estratégia surte efeito negativo em outros processos essenciais para as mesmas. Ao diminuir sua área foliar, sua capacidade de competição por luz fica limitada, diminuindo a taxa fotossintética, o que resulta na aceleração da taxa de senescência das folhas, inibição do perfilhamento e ramificações, morte rápida dos perfilhos, assim como no retardamento do crescimento e desenvolvimento da planta, ocasionando uma redução significativa na produtividade (Araújo et al., 2010; Santos et al., 2012).

Em déficit hídrico, as plantas utilizam mecanismos fisiológicos e anato morfológicos que delongam a sua desidratação (Duque et al., 2013). Dentre eles pode-se citar o ajustamento osmótico, que se 
constitui um dos mecanismos fisiológicos mais eficazes na manutenção da turgescência celular, quando a planta se encontra em ambiente com baixo potencial de água no solo e por curtos períodos de tempo, ou seja, quando as condições favoráveis não demoram a se normalizar (Monteiro et al., 2014). De acordo com Ashraf et al., (2011) e Pintó-Marijuan \& Munné-Bosch (2013), o ajustamento osmótico se estabelece na planta por meio do acúmulo de solutos compatíveis (prolina, glicina betaína, trealose, sacarose, poliaminas, manitol, pinitol entre outros), que mantêm o equilíbrio hídrico e a integridade de proteínas, enzimas e membranas celulares. De acordo com Monteiro et al., (2014), dentre estes solutos compatíveis, a prolina além de conferir maior tolerância ao estresse hídrico, pode atuar também como osmólito indicador fisiológico e bioquímico dos efeitos ocasionado pelo déficit hídrico em plântulas e guandu (Cajanus cajan). Outro mecanismo utilizado pelas plantas é a redução da área foliar, considerado por muitos como um dos efeitos mais drásticos do déficit hídrico, uma vez que acomete um decréscimo na fotossíntese e, consequente redução no crescimento das plantas (Taiz \& Zeiger 2009).

A redução da área foliar é principalmente influenciada pela pressão de turgescência das células, que por sua vez é determinado pelo conteúdo de água na planta. Logo, quanto menor for o conteúdo de água presente na planta, menor será o turgor das células, o que acarreta uma menor taxa de crescimento das folhas (Cavalcante et al., 2009). A redução da área foliar em resposta ao déficit hídrico em forrageiras foi observada em cultivares de Brachiaria brizantha (Marandú e BRS piatã) (Santos et al., 2013), Brachiaria brizantha Stapf. (BRA 004308, BRA 004367, BRA 006866 e BRA 007277) (Ribeiro et al., 2009). Maiores reduções da taxa de alongamento foliar foram observados nos genótipos Marandú e Xaraés, 94\% e 93\%, respectivamente, quando comparados com as cultivares BRS Piatã e BRS Paiaguás, $64 \%$ e $81 \%$, nessa ordem, quando submetidas ao estresse por deficiência hídrica (Pezzopane et al., 2015). As plantas podem ainda adaptar-se à seca por meio da produção de folhas menores e abscisão foliar (Cavalcante et al., 2009). Outro mecanismo fisiológico de proteção á desidratação imediata é o fechamento estomático, que reduz a perda de água das folhas pelo processo de transpiração (Conforto 2008; Taiz \& Zeiger 2009). Ao avaliar três genótipos de capim elefante anão, submetidos a duas condições de disponibilidade hídrica, Araújo et al., (2010) observaram uma redução da condutância estomática e, consequente, diminuição da transpiração nas plantas não irrigadas (Figura 3A e 3B), indicando que o estresse hídrico causado por déficit, causou o fechamento estomático e reduziu a perda de água pela planta.
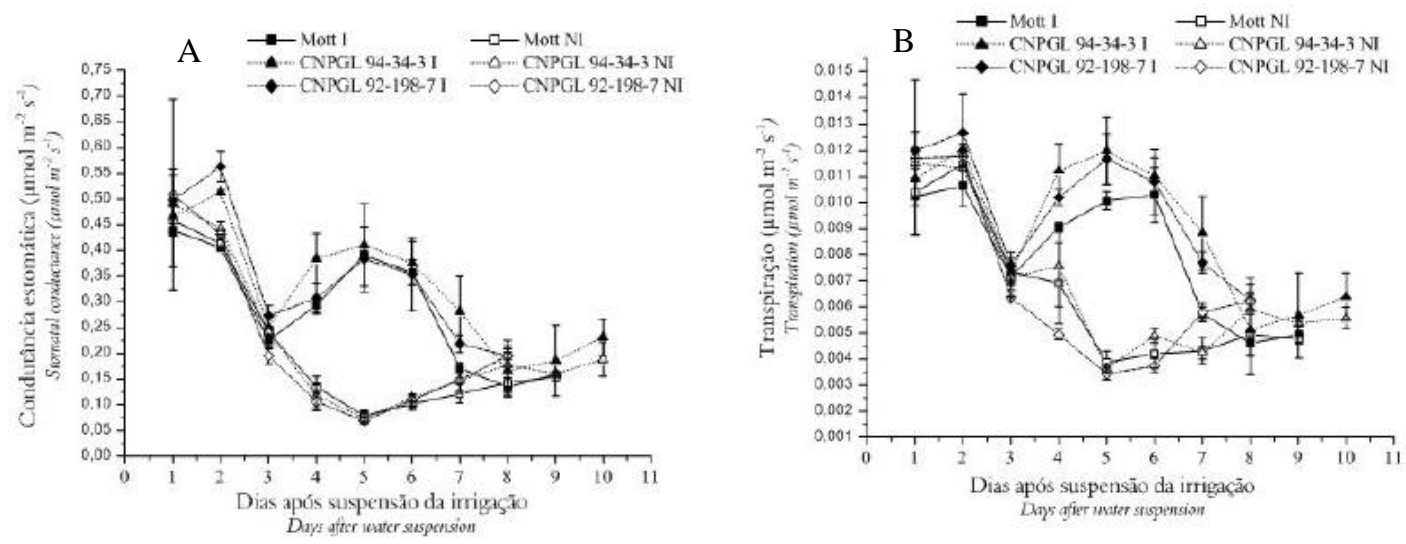

Figura 3. Condutância estomática (A) e transpiração (B) de genótipos de capim-elefante anão irrigado (I) e não irrigado (N). Fonte: Araújo et al., (2010).

As raízes quando submetidas às condições de déficit hídrico tendem a crescer até alcançar as zonas mais úmidas do solo (Pezzopane et al., 2015). Este comportamento foi observado em cultivares de Brachiaria brizantha (Marandú e BRS Piatã), o que possibilitou uma maior tolerância ao déficit hídrico (Santos et al., 2013). É provável ainda observar modificações anatômicas e estruturais nas plantas, tais como a mudança de folhas para espinhos, a existência de pêlos e a presença de substâncias como a cera, que funciona como uma barreira no limbo foliar, diminuindo a perda de água por transpiração. Essas características são notáveis em maior escala em plantas xerófitas, dentre elas, as cactáceas (Cavalcante et al., 2009). 
Nas cactáceas, em especial na palma forrageira, é possível observar mecanismos fisiológicos peculiares, como o metabolismo ácido das crassuláceas (MAC), o que lhe confere um alto rendimento em condições de déficit hídrico. Característica peculiar desse tipo de metabolismo, a palma forrageira abre seus estômatos à noite e os fecham durante o dia. Assim, ao absorverem o $\mathrm{CO}_{2}$ atmosférico na parte da noite, minimizam a perda de água e, consequentemente, podem apresentar alta eficiência no uso da água (EUA) (Vasconcelos et al., 2009; Leite et al., 2014). No EUA ou na tolerância a deficiência hídrica, as plantas utilizam mecanismos fisiológicos e anatômicos que retardam a desidratação (Duque et al., 2013). De acordo com Marenco \& Lopes (2005) e Kerbauy (2008), estudos mostram que a palma forrageira quando comparada com plantas de metabolismo C3 e C4, se destaca no quesito EUA, uma vez que o volume deste líquido chega próximo de 50:1, ou seja, para cada quilograma de matéria seca (MS) produzida, são gastos $50 \mathrm{~kg}$ de água, enquanto que as C3 e C4 para produzir a mesma quantidade de MS, precisam de 1000 e $500 \mathrm{~kg}$ de água, respectivamente, sendo que os valores de eficiência podem variar, pois depende da espécie e das condições locais. Silva et al., (2014) observaram que o clone Orelha de Elefante Mexicana (OEM) do gênero Opuntia, apresentou maior eficiência no uso da água para produzir matéria fresca, quando comparada com os clones Miúda (MIU) e Ipa Sertânia (IPA), ambas do gênero Nopalea. Por outro lado, quando observado a EUA em relação a evapotranspiração real da cultura (ETr), além do clone OEM, a IPA também apresentou eficiência.

\section{Práticas de convivência com estresse hídrico}

É de amplo conhecimento que as espécies vegetais necessitam de condições edafo-climáticas adequadas, para que possam crescer e se desenvolverem de forma satisfatória, no entanto, nem sempre é possível atender tais condições. Diante disso, torna-se indispensável o conhecimento de práticas de manejo que possibilite um bom desempenho produtivo das culturas forrageiras em condições adversas. Dentre os manejos adotados que visam à redução de perdas nos sistemas produtivos e/ou aumentar o rendimento anual das culturas, a irrigação torna-se uma alternativa a ser utilizada (Santos et al., 2008). Embora seja usada somente como uma prática de seguro contra secas, quando realizada adequadamente, proporciona ao material genético, condições favoráveis para expressar no campo todo o seu potencial produtivo (Ribeiro et al., 2008; Alencar et al., 2009). Vitor et al., (2009) observaram aumento significativo na produção de massa seca do Capim-Elefante submetido a irrigação no período seco e em períodos de veranico. Por outro lado, a irrigação suplementar não promoveu incrementos significativos sobre a produção e qualidade de outras gramíneas forrageiras (Santos; Silva; Chaves, 2008). Atrelado a isso, o uso de cobertura morta na superfície do solo é de grande valia para a agricultura irrigada. Quando colocada em quantidade adequada, melhora a eficiência do uso de água, através da redução da taxa evaporativa do solo e da evapotranspiração das culturas, principalmente nos estádios em que o dossel destas não cobre totalmente a superfície. Além disso, proporciona o aumento da retenção de água no solo, reduzindo a frequência de irrigação e aumentando a economia nos custos de operação do sistema (Resende et al., 2005; Oliveira Neto et al., 2011).

\section{Considerações finais}

A compreensão de como as plantas responde aos danos provocados pelo estresse hídrico é sem dúvida um importante ponto para que estratégias de manejo sejam desenvolvidas, tendo em vista o favorecimento da constância e produtividade das plantas forrageiras em condições adversas ao seu cultivo. Foi possível observar que as plantas desenvolvem mecanismos que as fazem tolerar o estresse hídrico. No entanto, alguns mecanismos interferem diretamente no desenvolvimento e produtividade das culturas forrageiras, como por exemplo, o fechamento dos estômatos e a redução da área foliar, uma vez que participam de forma direta do processo de fotossíntese. Por outro lado, o ajustamento osmótico é responsável pela produção de osmólitos orgânicos, em especial a prolina, substância essa que confere resistência, além de funcionar como substância fisiológica e bioquímica indicativa de estresse nas plantas.

O planejamento agrícola que dá subsídio ao produtor a plantar em períodos favoráveis e o uso de espécies tolerantes, são alternativas que em consonância com a irrigação racional e o uso de cobertura morta, podem proporcionar as forrageiras boas condições de cultivo e assim, diminuir os danos 
oriundos do déficit hídrico, podendo ainda, incrementar a produtividade das culturas mesmo em períodos com baixa disponibilidade hídrica.

Estudos com déficit hídrico em forrageiras são de grande importância prática, pois certas informações auxiliam os técnicos e produtores a escolherem a forrageira adequada, assim como o manejo que devem utilizar nessas condições. No entanto, é necessário maiores informações, principalmente em relação a forrageiras nativas da caatinga, uma vez que essa vegetação é a base alimentar dos rebanhos na região semiárida.

\section{Referências bibliográficas}

Alencar C.A.B., Cunha F.F., Martins C.E., Cóser A.C., Rocha W.S.D. \& Araújo R.A.S. (2009). Irrigação de pastagem: atualidade e recomendações para uso e manejo. Revista Brasileira de Zootecnia 38, 98-108.

Angelocci L.R. (2002). Água na planta e trocas gasosas/energéticas com a atmosfera: Introdução ao tratamento biofísico. FEALQ, Piracicaba, São Paulo, Brasil.

Araújo Filho J.A. \& Carvalho F.C. (1997) Desenvolvimento sustentável da caatinga. Sobral: EMBRAPACNPC 1, 1-17.

Araújo Filho J.A., Sousa F.B. \& Carvalho F.C. (1995). Pastagens no semi-árido: pesquisa para o desenvolvimento sustentável. Simpósio Sobre Pastagens Nos Ecossistemas Brasileiros 22, 28-62.

Araújo S.A.C., Vasquez H.M., Campostrini E., Netto A.T., Deminicis B.B. \& Lima É.S. (2010). Características fotossintéticas de genótipos de capim-elefante anão (Pennisetum purpureum Schum.), em estresse hídrico. Acta Scientiarum: Animal Sciences, 1-7.

Ashraf M., Akram N.A., Al-Qurainy F. \& Foolad M.R. (2011). Drought tolerance: roles of organic osmolytes, growth regulators, and mineral nutrients. Advances in Agronomy 111, 249-296.

Balardin R.S., Silva F.D.L., Debona D., Corte G.D., Favera D.D. \& Tormen N.R. (2011) Tratamento de sementes com fungicidas e inseticidas como redutores dos efeitos do estresse hídrico em plantas de soja. Ciência Rural 41, 1120-1126.

Bilibio C., Carvalho J.A., Martins M., Rezende F.C., Freitas E.A. \& Gomes L.A.A. (2010). Desenvolvimento vegetativo e produtivo da berinjela submetida a diferentes tensões de água no solo. Revista Brasileira de Engenharia Agricola e Ambiental 14, 730-735.

Blum A., Johnson J.W., Ramseur E.L. \& Tollner E.W. (1991). The effect of a drying top soil and a possible non-hydraulic root signal on wheat growth and yield. Journal of Experimental Botany 42, $1225-1231$.

Cavalcante A.C.R., Cavallini M.C. \& Lima N.R.C.B. (2009). Estresse por déficit hídrico em plantas forrageiras. Embrapa Caprinos e Ovinos.

Chavarria G. \& Santos H.P. (2012). Plant water relations: absorption, transport and control mechanisms. In: Advances in selected plant physiology aspects (eds. by Montanaro G \& Dichio B), pp. 105-132. Rijeka: Intech.

Conforto C. (2008). Respostas fisiológicas ao déficit hídrico em duas cultivares enxertadas de seringueira (" RRIM 600. Ciência Rural 38, 679-684.

Costa J.R., Pinho J.L.N. \& Parry M.M. (2008). Produção de matéria seca de cultivares de milho sob diferentes níveis de estresse hídrico. Revista Brasileira de Engenharia Agricola e Ambiental 12, 443-450.

Duque A.S., Almeida A.M., Silva A.B., Silva J.M., Farinha A.P., Santos D., Fevereiro P. \& Araújo S.S. (2013). Abiotic stress responses in plants: unraveling the complexity of genes and networks to survive. In: Abiotic stress-plant responses and applications in agriculture (InTech.

Endres L., Silva J.V., Ferreira V.M. \& Barbosa G.V.S. (2010). Photosynthesis and water relations in Brazilian sugarcane. The Open Agriculture Journal 4, 31-37.

Galmés J., Ribas-Carbó M., Medrano H. \& Flexas J. (2011). Rubisco activity in Mediterranean species is regulated by the chloroplastic $\mathrm{CO} 2$ concentration under water stress. Journal of Experimental Botany 62, 653-665. 
Jones H.G. \& Jones M.B. (1989). Introduction: some terminology and common mechanisms. In: Plants under stress: biochemistry, physiology, ecology, and their applications to plant improvement (eds. by Jones HG, Flowers M \& Jones MB), pp. 1-10. Cambridge University Press, Cambridge, UK.

Kerbauy G.B. (2008). Fisiologia Vegetal. Guanabara Koogan, Rio de Janeiro, Brasil.

Lehninger N.D.L. (2006). Principios de bioquímica. São Paulo.

Leite M.L.M.V., Silva D.S., Andrade A.P., Pereira W.E. \& Ramos J.P.F. (2014). Caracterização da produção de palma forrageira no Cariri paraibano. Revista Caatinga 27, 192-200.

Marenco R.M. \& Lopes N.F. (2005). Fisiologia vegetal: fotossintese respiracao relacoes hidricas nutricao mineral. Universidade Federal de Viçosa, Viçosa, Minas Gerais, Brasil.

Monteiro J.G., Cruz F.J.R., Nardin M.B. \& Santos D.M.M. (2014). Crescimento e conteúdo de prolina em plântulas de guandu submetidas a estresse osmótico e à putrescina exógena. Pesquisa Agropecuária Brasileira 49, 18-25.

Oliveira A.R., Braga M.B. \& Walker A.M. (2015). Comportamento vegetativo e qualidade tecnológica de cultivares de cana-de-açúcar submetidas ao estresse hídrico em condições Semiáridas do Brasil. Revista Brasileira de Geografia Física 8, 525-541.

Oliveira Neto D.H., Carvalho D.F.D., Silva L.D., Guerra J.G.M. \& Ceddia M.B. (2011). Evapotranspiração e coeficientes de cultivo de beterraba orgânica sob cobertura morta de leguminosa e gramínea. Revista Horticultura Brasileira 29, 330-334.

Pezzopane C.G., Santos P.M., Cruz P.G., Altoé J., Ribeiro F.A. \& Valle C.B. (2015). Hydric deficiency in genotypes of Brachiaria brizantha. Ciência Rural 45, 871-876.

Pimentel C. (2004). Funções da água. In: A relação da planta com a água (ed. by Pimentel C), pp. 4857. Edur, Seropédica, Rio de Janeiro, Brasil.

Pintó-Marijuan M. \& Munné-Bosch S. (2013). Ecophysiology of invasive plants: osmotic adjustment and antioxidants. Trends in plant science 18, 660-666.

Resende F.V., Souza L.S., Oliveira P.S.R. \& Gualberto R. (2005). Uso de cobertura morta vegetal no controle da umidade e temperatura do solo, na incidência de plantas invasoras e na produção da cenoura em cultivo de verão. Revista Ciência Agrotecnológica 29, 100-105.

Ribeiro E.G., Alencar F.C.A., Bergottini J.G., Palieraqui C.E.M., Cóser A.C. \& Faria S.A.N. (2008). Influência da irrigação durante as épocas seca e chuvosa na taxa de lotação, no consumo e no desempenho de novilhos em pastagens de capim-elefante e capim-mombaça. Revista Brasileira de Zootecnia 37, 1546-1554.

Ribeiro J.L., Nussio L.G., Mourão G.B., Queiroz O.C.M., Santos M.C. \& Schmidt P. (2009). Efeitos de absorventes de umidade e de aditivos químicos e microbianos sobre o valor nutritivo, o perfil fermentativo e as perdas em silagens de capim-marandu. Revista Brasileira de Zootecnia 38, 230239.

Santos D., Guimarães V.F., Klein J., Fioreze S.L., Junior M. \& Eurides K. (2012). Cultivares de trigo submetidas a déficit hídrico no início do florescimento, em casa de vegetação. Revista Brasileira de Engenharia Agricola e Ambiental 16, 836-842.

Santos M.C.S., Lira M.A., Tabosa J.N., Mello A.C.L. \& Santos M.V.F. (2011). Comportamento de clones de Pennisetum submetidos a períodos de restrição hídrica controlada. Archivos de zootecnia 60, 31-39.

Santos N.L., Silva M.W.R. \& Chaves M.A. (2008). Efeito da irrigação suplementar sobre a produção dos capins tifton 85, tanzânia e marandu no período de verão no sudoeste baiano. Ciência Animal Brasileira 9, 911-922.

Santos P.M., Cruz P.G., Araujo L.C., Pezzopane J.R.M., Valle C.B.d. \& Pezzopane C.d.G. (2013). Response mechanisms of Brachiaria brizantha cultivars to water deficit stress. Revista Brasileira de Zootecnia 42, 767-773.

Silva E.M.B., Silva T.J.A., Cabral C.E.A., Kroth B.E. \& Rezende D. (2011). Revista Caatinga. 242. 
Silva T.G.F., Primo J.T.A., Silva S.M.S., Moura M.S.B., Santos D.C., Silva M.C. \& Araújo J.E.M. (2014). Indicadores de eficiência do uso da água e de nutrientes de clones de palma forrageira em condições de sequeiro no Semiárido brasileiro. Revista Bragantia 73, 184-191.

Smit M.A. \& Singels A. (2006). The response of sugarcane canopy development to water stress. Field Crops Research 98, 91-97.

Taiz L. \& Zeiger E. (2009). Fisiologia vegetal. Artmed, Porto Alegre, Brasil.

Vasconcelos A.G.V., Lira M.A., Cavalcanti V.L.B., Santos M.V.F. \& Willadino L. (2009). Seleção de clones de palma forrageira resistentes à cochonilha-do-carmim (Dactylopius sp). Revista Brasileira de Zootecnia 38, 827-831.

Vitor C.M.T., Fonseca D.d., Cóser A.C., Martins C.E., Nascimento Júnior D. \& Ribeiro Júnior J. (2009). Produção de matéria seca e valor nutritivo de pastagem de capim-elefante sob irrigação e adubação nitrogenada. Revista Brasileira de Zootecnia 38, 435-442.

Recebido: 10 novembro, 2018.

Aprovado: 26 novembro, 2018

Publicado: 31 dezembro, 2018.

Licenciamento: Este artigo é publicado na modalidade Acesso Aberto sob a licença Creative Commons Atribuição 4.0 (CC-BY 4.0), a qual permite uso irrestrito, distribuição, reprodução em qualquer meio, desde que o autor e a fonte sejam devidamente creditados. 